\title{
Risk of Developing T2DM among Students of Graduation and Undergraduation Courses in Andhra Pradesh: An Evaluation using Indian Diabetes Risk Score (IDRS)
}

\author{
Alan Rose Janga, Jyothi Naga Mohana Sathineni*, Siva Bharath Gavini, Jai Divya Tella, Ramarao Nadendla
}

\begin{abstract}
Background: Diabetes Mellitus is a major public and clinical health concern. It is a basic knowledge thatT2DM causes a serious decline in normal Quality of Life, where late identification in later ages is the major challenge. The main motive of this study was to evaluate a pre-existing multivariate risk factors for the development of Type 2 Diabetes Mellitus in youth. Objectives: To predict and assess the risk and risk factors for Type 2 Diabetes Mellitus. Methods: The study was designed to be a cross-sectional epidemiological study. It was conducted in the students of graduation and under graduation courses in Guntur District, Andhra Pradesh over 6 months from $1^{\text {st }}$ September 2019 to $1^{\text {st }}$ February 2020 which includes 2524 students with a response rate of $92.5 \%$. Students are enrolled based on Inclusion and exclusion criteria. Specially designed data collection form used to obtain the data required for the study. Results: In our study we have collected data from 2524 students where, 1088 students $(34.50 \%)$ were males and 1435 (65.49\%) were females. Diabetes risk was assessed using validated tool, Indian Diabetes Risk Score. Conclusion: We came to a conclusion that most of the students have moderate to low risk of diabetes mellitus, with significantly contributing risk factors like family history, low PA.

Key words: Andhra Pradesh, Diabetes risk, Family history, IDRS, India, Students, Youth.
\end{abstract}

\section{Alan Rose Janga, Jyothi
Naga Mohana Sathineni*, \\ Alan Rose Janga, Jyothi
Naga Mohana Sathineni*, Siva Bharath Gavini, Jai Divya Tella, Ramarao Nadendla \\ Department of Pharmacy Practice, Chalapathi Institute of Pharmaceutical Sciences, Lam, Guntur, Andhra Pradesh, INDIA.}

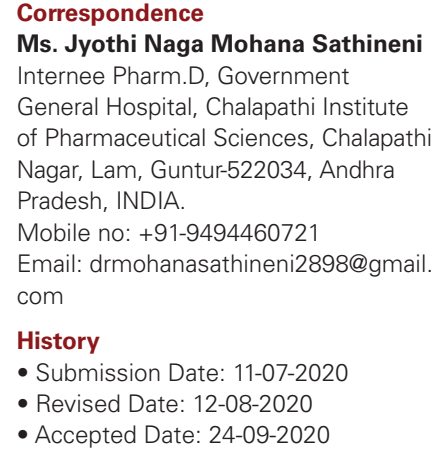
INTRODUCTION

Type 2 diabetes mellitus (T2DM) is one of the most widely recognized chronic disorders that represent a genuine social and monetary issue at present in numerous nations regardless of the degree of improvement. ${ }^{1}$ As expressed by the International Diabetes Federation (IDF), around 415 million grown-ups between the ages of 20 to 79 years had T2DM in $2015 .^{2}$ Diabetes mellitus was so normal among all age groups that were currently being analyzed in teenagers, kids and even in more youthful population as of late Incidence is a lot of hard to gauge than prevalence. T2DM is the most settled type of DM, which represents $90 \%$ to $95 \%$ of every single diabetic patient and is relied upon to increment to 439 million by $2030 .^{3}$ In the event that any of the individuals in your family have diabetes, you may have a hereditary composition to the circumstance. The risk factors for the hereditary appearance including raising $\mathrm{BP}$, obesity, physical activity, decline in the admission of protein diet, increment in midriff boundary may have an energetic opportunity to get T2DM. This incessant(chronic) condition as a metabolic issue results from the tissue resistance to insulin as a result of low physical movement level and robustness, which are regular of individuals in their mature age, yet now it is ordinarily found in youths, youngsters and more youthful grown-ups than more established individuals. ${ }^{4}$

\section{Indian Diabetes Risk Score}

The Indian Diabetes Risk Score (IDRS) was conceived by the Madras Diabetes Research Foundation. It is a powerful diabetes screening tool which includes family history, abdomen obesity, age and physical activity of the person. Consequently, individual with high risk of developing diabetes mellitus in near future can be distinguished and methodical counseling and further interventions can be applied so as to lessen diabetes related complications. ${ }^{5}$ The current study was done to assess and spread the awareness with respect to risk for type 2 diabetes mellitus utilizing IDRS of MITS College, Gwalior having age group 18-25 yrs. Risk Interpretation was done as high, moderate and low risk if their IDRS score is $\geq 60,30-50$ and $<30$ respectively. ${ }^{5}$

\section{MATERIAL AND METHODS}

This is an epidemiological cross-sectional observational study carried out in different graduation and post-graduation colleges located in and around Guntur district, Andhra Pradesh. It covers a total population of 2523 students pursuing
Cite this article : Janga AR, Sathineni JNM, Gavini SB, Tella JD, Nadendla R. Risk of Developing T2DM among Students of Graduation and Undergraduation Courses in Andhra Pradesh: An Evaluation using Indian Diabetes Risk Score (IDRS). Int J Med Public Health. 2020;10(4):198-201. 
both under graduation and post-graduation courses. The study was conducted for a period of 6 months from September 2019 to February 2020. The subjects included were adult students aged from 18 to 24 yrs. Subjects were categorized into males and females.

Informed consent form was gathered from each head of the institutions as a whole from each student. Students with diabetes mellitus and other disease and females who are pregnant were excluded from the study.

Following data was collected from subjects in the stepwise manner from a predesigned data collection form, each participant was questioned for age, educational status, physical activity, gender, family history, waist circumference.

Abdominal obesity (waist circumference) was measured using standard measuring tapes, height $(\mathrm{cm})$ and weight $(\mathrm{kg})$ for calculating BMI were measured using digital BMI machine.

$$
n=\mathrm{Z}^{2} \mathrm{Pq} / \mathrm{d}^{2}
$$

Where, $z=$ standard normal deviate; 1.96 which correspond to $95 \% \mathrm{CI}$

$$
n=\mathrm{Z}^{2} \mathrm{Pq} / \mathrm{d}^{2} \quad=2184
$$

2725 students received a

questionnaire

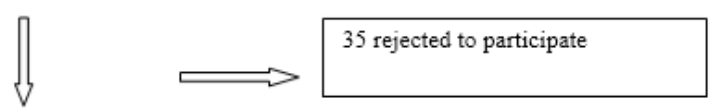

2690 studentscompleted the

questionnaire

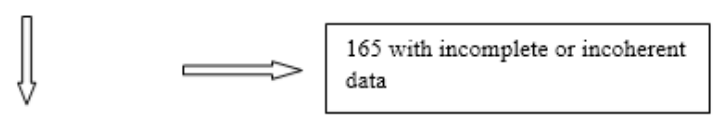

2523 students were included in

final analysis

Figure 1: Profile of the inclusion and exclusion process.

\begin{tabular}{|c|c|c|}
\hline \multicolumn{3}{|c|}{ Components of Indian Diabetes Risk Score (IDRS) } \\
\hline Risk Factors & Score & \\
\hline \multicolumn{3}{|l|}{ Age } \\
\hline$<35$ & 0 & \\
\hline $35-49$ & 20 & \\
\hline$>50$ & 30 & \\
\hline \multicolumn{3}{|l|}{ Abdominal Obesity } \\
\hline$<80 \mathrm{~cm}$ (females) $<90 \mathrm{~cm}$ (males) & 0 & \\
\hline $\begin{array}{l}\geq 80-89 \mathrm{~cm} \text { (females) } \geq 90-99 \mathrm{~cm} \\
\text { (males) }\end{array}$ & 10 & \\
\hline$\geq 90 \mathrm{~cm}$ (females) $\geq 100 \mathrm{~cm}$ (males) & 20 & \\
\hline \multicolumn{3}{|l|}{ Physical Activity } \\
\hline Exercise regular + strenuous work & 0 & \\
\hline Exercise regular or strenuous work & 20 & \\
\hline No exercise and sedentary work & 30 & \\
\hline \multicolumn{3}{|l|}{ Family History } \\
\hline No family history & 0 & \\
\hline Either parent & 10 & \\
\hline \multirow[t]{2}{*}{ Both parents } & 20 & \\
\hline & & $\begin{array}{r}\text { Minimum score: } 0 \\
\text { Maximum score: } 100\end{array}$ \\
\hline
\end{tabular}

Table 1: Indian Diabetes Risk Score.
The study subjects were scored according to the following score. ${ }^{6}$

\section{Sample Size}

The sample size was estimated using results from the pilot study we conducted with 50 students. Among them 65\% had moderate to high risk score. The sample size was estimated using the formula

\section{Statistical Analysis}

Data were entered using Microsoft excel and analyzed using the SPSS version 25. Quantitative data were expressed as mean, standard deviation and $95 \%$ confidence interval (CI) was calculated. Descriptive data were expressed as percentage/proportion. We used chi-square tests to compare categorical variables. ' $P$ ' $<0.05$ was considered statistically significant.

\section{Ethical Considerations}

Ethical clearance was taken from the Institutional Ethics Committee, government medical college, Guntur. Written informed consent was taken from study participants. Confidentiality of the collected information was maintained throughout the study and data were utilized for this research only.

\section{RESULTS}

Out of 2725 questionnaires distributed to students at nearly 12 colleges, in and around Guntur, Andhra Pradesh. Out of which, 201 were excluded, among them 35 students rejected to participate and 166 due to missing or incoherent information in the questionnaire. Thus, the final analysis included 2523 students, of whom 1087 students (34.50\%) were males and 1435 (65.49\%) were females (Figure 1). Descriptive data for the risk variables was mentioned along with their confidence values (Table 2). After the evaluation of data, it was found that majority of the

\begin{tabular}{|c|c|c|c|}
\hline Variable & $\mathrm{N}(\%)$ & Mean $\pm S D$ & $P$-value \\
\hline \multicolumn{4}{|l|}{ Abdominal Obesity } \\
\hline $\begin{array}{l}<80 \mathrm{~cm} \\
\text { (females) }<90 \mathrm{~cm} \\
\text { (males) }\end{array}$ & $1665(65.99 \%)$ & & \\
\hline $\begin{array}{l}\geq 80-89 \\
\mathrm{~cm} \text { (females) } \geq 90-99 \\
\mathrm{~cm} \text { (males) }\end{array}$ & $767(30.36 \%)$ & $3.7772 \pm 5.593$ & 0.006 \\
\hline $\begin{array}{l}\geq 90 \mathrm{~cm} \\
\text { (females) } \geq 100 \mathrm{~cm} \\
\text { (males) }\end{array}$ & $91(3.6 \%)$ & & \\
\hline \multicolumn{4}{|l|}{ Physical activity } \\
\hline $\begin{array}{l}\text { Exercise regular + } \\
\text { strenuous work }\end{array}$ & $539(21.36 \%)$ & & \\
\hline $\begin{array}{l}\text { Exercise regular or } \\
\text { strenuous work }\end{array}$ & $796(31.54 \%)$ & $20.435 \pm 11.506$ & 0.01 \\
\hline $\begin{array}{l}\text { No exercise and } \\
\text { sedentary work }\end{array}$ & $1188(47.08 \%)$ & & \\
\hline \multicolumn{4}{|l|}{ Family History } \\
\hline No family history & $1581(62.665)$ & 420 & \\
\hline Either parent & $826(32.73)$ & $4.2013 \pm J .001$ & 0.007 \\
\hline Both parents & $116(4.59 \%)$ & & \\
\hline
\end{tabular}

Table 2: Risk Factors Evaluation. 
Table 3: Interpretation of data as IDRS risk categories.

\begin{tabular}{|c|c|c|c|c|}
\hline & $\frac{a}{z}$ & 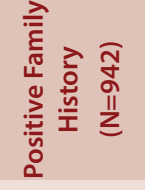 & 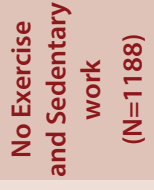 & 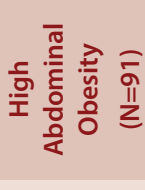 \\
\hline Low Risk & $846(33.5 \%)$ & $50(5.9 \%)$ & $168(19.8 \%)$ & 0 \\
\hline $\begin{array}{l}\text { Moderate } \\
\text { Risk }\end{array}$ & $1645(65.2 \%)$ & $862(52.4 \%)$ & $988(60 \%)$ & $60(3.6 \%)$ \\
\hline High Risk & $32(1.2 \%)$ & $30(93.7 \%)$ & $32(100 \%)$ & $31(96.8 \%)$ \\
\hline
\end{tabular}

$p$ - value $<0.05$ is statistically significant ${ }^{*}$

Table 4: Risk Categorization and Gender.

$\begin{array}{cccccc} & \text { Males } & \begin{array}{c}P \text { - } \\ \text { value }\end{array} & \text { Females } & P \text {-Value } & X^{2} \text {-value } \\ \text { High Risk } & 66 \pm 5.16 & 0.1023 & 61.81 \pm 3.94 & 0.0527 & 0.601 \\ \text { Moderate Risk } & 34.76 \pm 6.32 & 0.0147 & 35.66 \pm 6.79 & 0.0140 & \\ \text { Low Risk } & 9.8 \pm 8.8 & 0.0292 & 14.4 \pm 7.39 & 0.02099 & \end{array}$

$P$-value $<0.05$ is statistically significant ${ }^{*}$

subjects fall under moderate risk (65.2\%) and low risk (33.5\%) category with $1 \%$ of high risk of developing T2DM. (Table 3)

\section{DISCUSSION}

A cost-effective and simple IDRS tool was used, which is able to predict the diabetes risk. Present study was conducted in 2524 students and revealed that $846(33.5 \%), 1645(65.2 \%), 32(1.26 \%)$ subjects were in low-, moderate- and high- risk category as per IDRS. Similarly, Pangtey $\mathrm{R}$ et al. in their study reported that 222 (77\%), 67 (22\%) and 1 (1\%) subjects were in low-, moderate- and high-risk category when assessed with IDRS, respectively. Their study findings revealed that large number (23\%) of young medical students were in moderate-high risk category of developing T2DM and health care professionals should be more vigilant in young obese males with minimal physical activity and positive family history of disease. ${ }^{7}$ Higher numbers for moderate-risk category were found in the studies conducted by Subramani et al. (74.7\%), Bhatia et al. (68\%), Mohan et al. (50.3\%) and Chowdhury et al. (46\%). ${ }^{8-11}$ Positive family history plays a vital role in occurrence of diabetes. In our study also, high to moderate risk category for T2DM gave a positive family history $(p=0.007)$ and $\mathrm{BMI}>23 \mathrm{Kg} / \mathrm{m}^{2}$ (overweight to extreme obesity) as major contributing risk factors. Other covariates for diabetes were increased abdomen obesity $(p=0.007)$, low to no physical activity $(p=0.01)$, which have been significantly associated with risk of T2DM from results of IDRS in our study.

According to Dudeja P, et al. IDRS has a sensitivity of $95.12 \%$ and specificity of $28.9 \%$ when the score is 60 and above. ${ }^{5}$ Our study was a population-based with a large sample size, which is likely to be representative of the student community, which means that a significant proportion of young students in Andhra Pradesh are likely to develop T2DM.

Our results have shown no significant difference between the genders i e. There is same proportion of risk for developing T2DM both in males as well as females (Table 4). Also, the impact of positive family history for T2DM and low or no physical activity noted to be significant. By these results we came to know that family history, physical activity and waist circumference are the major contributing risk factors in developing
T2DM in later ages. As all the subjects included in the study were under $35 y r s$ of age, the score is already 0 . Hence, age cannot be considered a risk variable.

Most of the subjects under moderate-high risk category of T2DM had positive family history for both or either parents, no physical activity and high abdominal obesity (supportive BMI $>24 \mathrm{~kg} / \mathrm{m}^{2}-46 \%$ ).

This study helped in gaining knowledge about health status of the youth in Andhra Pradesh.

Recognizing these risk factors has a vital role in general wellbeing as it assists with diminishing the time slack between exposure and disease.

Hence it is very important to have a knowledge and awareness about all these risk factors and T2DM among youth, could be a great help to reduce the increasing numbers of incident diabetes among youth and adults.

\section{Future Scope}

A lot of works lies ahead in understanding risk factors for developing T2DM. This work is essential for identifying chances for being a risk factor for developing T2DM in youth. We have only begun to understand the role of family history and BMI, increased risk of T2DM in youth, but several on-going follow-up studies may add to our understanding towards contribution of these risk factors and will improve strength for our study.

\section{CONCLUSION}

In conclusion, our study using IDRS is very helpful for health education and lifestyle modification which are the major risk factors, as lack of knowledge on health, life style and dietary patterns were emerging as the major risk factors for developing metabolic diseases, at present as T2DM. Most of the students included in the study, found to have moderate to low risk of T2DM, having positive family history and other factors like BMI, PA have shown a major contribution. Awareness was done to the students regarding all the risk factors, malnutrition and T2DM, which are under moderate to high risk category. High risk category, recommended for regular follow-up and checkups and were informed regarding all the future possibilities and probability of getting T2DM, if neglected any healthy recommendations.

\section{LIMITATIONS}

- $\quad$ The risk evaluation was generally put together both with respect to subjective and objective evaluations. Our assessment is solely based on the answer given by the subject.

- We didn't measure fasting blood glucose in all members and in this manner, we couldn't evaluate the specific sensitivity and specificity of IDRS right now.

- Lack of knowledge regarding diabetes among students could be the major reason for under-reporting of family history.

- Its cross-sectional structure of the study doesn't permit us to evaluate the reason impact connection between the fluctuation of diabetes risk and the nutritional status of subjects under investigation.

\section{STRENGTHS}

$\checkmark$ The major strength of this study was the large sample size and the high response rate of $92.5 \%$, which probably means it can be representative of the population studied.

$\checkmark$ Cross evaluation and reconfirmation of data with the subjects was done to avoid bias, since the data is dependent on knowledge of subjects. 


\section{ACKNOWLEDGEMENT}

We are grateful to the students who took part in the study and principal of the Chalapathi Institute of Pharmaceutical Sciences for supporting us to carry out study at different institutions and respective head of the institutions who facilitated the study at their premises.

\section{CONFLICT OF INTEREST}

The authors declare that there is no conflict of interest.

\section{ABBREVIATIONS}

T2DM: Type 2 Diabetes Mellitus; IDRS: Indian Diabetes Risk Score; BMI: Body Mass Index.

\section{REFERENCES}

1. Zabuga OG, Vaiserman AM. Malnutrition in Early Life and Risk of Type 2 Diabetes: Theoretical Framework and Epidemiological Evidence, Mascow. University Biological Sciences Bulliten. 2017;72(2):37-46.

2. DOI: $10.3103 / 80096392517020067$

3. Available At Http://Ncp.Sagepub.Com/Content/23/4/388

4. Zheng Y, Ley SH, Hu FB. Global aetiology and epidemiology of type 2 diabetes mellitus and its complications. Nat Rev Endocrinol. 2018;14(2):88-98.
5. Wu Y, Ding Y, Tanaka Y, g Zhang W.Risk Factors Contributing to Type 2 Diabetes and Recent Advances in the Treatment and Prevention. Int J Med Sci. 2014;11(11):1185-200. doi: 10.7150/ijms.10001.

6. Dudeja P, Singh G, Gadekar T, Mukherji S. Performance of Indian diabetes risk score (IDRS) as screening tool for diabetes in an urban slum. Med J Armed Forces India. 2016. Available at http://dx.doi.org/10.1016/j.mjafi.2016.08.007

7. Sahai S, Ahuja N. Risk Of Developing Diabetes In The Indian Youth: An Evaluation Using Indian Diabetes Risk Score (IDRS). International Journal of Medical and Health Research. 2017;3(5):17-9.

8. Vivian ME, Carrel LA, Becker T. Identifying Children at Risk for Type 2 Diabetes in Underserved Communities. Diabetes Education. 2011;37(4):519-27.

9. DOI: $10.1177 / 0145721711406139$

10. Singh MM, Mangla $V$, Pangtey R, Garg S. Risk assessment of diabetes using the Indian diabetes risk score: A study on young medical students from Northern India. Indian J Endocr Metab. 2019;23(1):86-90.

11. Subramani R, Devi U, Shankar U, Stephen T, Karthik RC, Seshadhri S, et al. Assessment of risk of type 2 diabetes mellitus among rural population in Tamil Nadu by using Indian Diabetic Risk Score. Middle-East J Sci Res. 2014;21(1):223-5

12. Bhatia T, Maitreyi O, Vimisha D, Sonalika B, Gerhard F Vaidehi L, et al. Type 2 diabetes mellitus: Risk evaluation and advice in undergraduate students in Mumbai. Int J Pharm Sci Invent. 2014:3:37-40

13. Mohan V Sandeep S, Deepa R, Shah B, Varghese C. Epidemiology of type 2 diabetes: Indian scenario. Indian J Med Res. 2007;125(3):217-30.

14. Chowdhury R, Mukherjee A, Lahiri SK. A study on distribution and determinants of Indian Diabetic Risk Score (IDRS) among rural population of West Bengal. National J Med Res. 2012;2(3):282-6.

Cite this article : Janga AR, Sathineni JNM, Gavini SB, Tella JD, Nadendla R. Risk of Developing T2DM among Students of Graduation and Undergraduation Courses in Andhra Pradesh: An Evaluation using Indian Diabetes Risk Score (IDRS). Int J Med Public Health. 2020;10(4):198-201. 